Challenge of paediatric compounding to solid dosage forms sachets and hard capsules - Finnish perspective

\title{
Siven, Mia
}

2017-05

Siven , M , Kovanen , S , Siirola , O , Hepojoki , T , Isokirmo , S , Laihanen , N , Eränen , T , Pellinen , J \& Juppo , A M 2017 , ' Challenge of paediatric compounding to solid dosage forms sachets and hard capsules - Finnish perspective ' , Journal of Pharmacy and Pharmacology, vol. 69 , no. 5 , pp. 593-602 . https://doi.org/10.1111/jphp.12648

http://hdl.handle.net/10138/309088

https://doi.org/10.1111/jphp.12648

cc_by_nc

acceptedVersion

Downloaded from Helda, University of Helsinki institutional repository.

This is an electronic reprint of the original article.

This reprint may differ from the original in pagination and typographic detail.

Please cite the original version. 


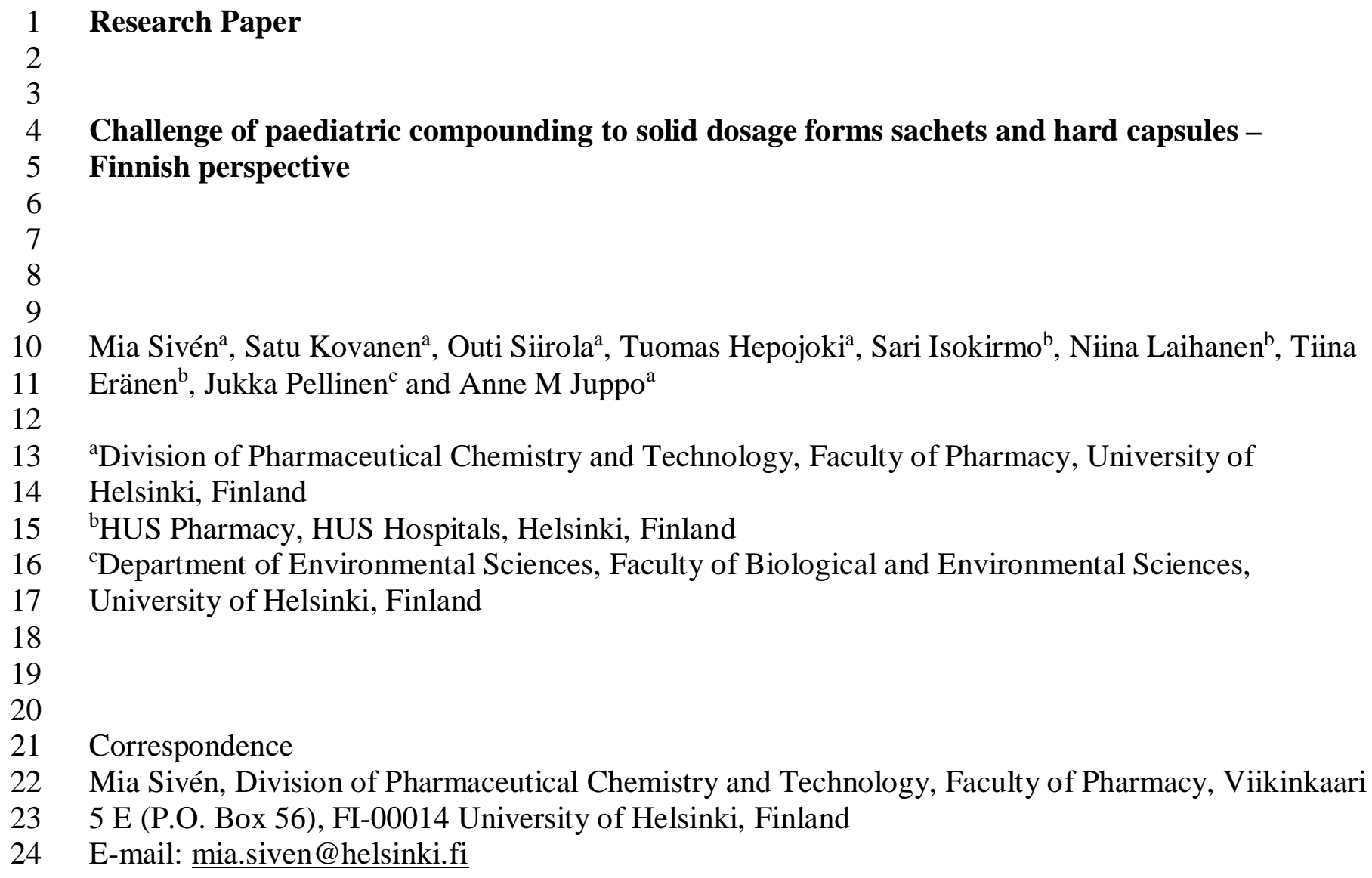

10 Mia Sivén $^{\mathrm{a}}$, Satu Kovanen ${ }^{\mathrm{a}}$, Outi Siirola ${ }^{\mathrm{a}}$, Tuomas Hepojoki ${ }^{\mathrm{a}}$, Sari Isokirmo ${ }^{\mathrm{b}}$, Niina Laihanen ${ }^{\mathrm{b}}$, Tiina 11 Eränen $^{\mathrm{b}}$, Jukka Pellinen ${ }^{\mathrm{c}}$ and Anne M Juppo ${ }^{\mathrm{a}}$

aDivision of Pharmaceutical Chemistry and Technology, Faculty of Pharmacy, University of Helsinki, Finland

15 bHUS Pharmacy, HUS Hospitals, Helsinki, Finland

16 'Department of Environmental Sciences, Faculty of Biological and Environmental Sciences, 17 University of Helsinki, Finland

Correspondence

Mia Sivén, Division of Pharmaceutical Chemistry and Technology, Faculty of Pharmacy, Viikinkaari 5 E (P.O. Box 56), FI-00014 University of Helsinki, Finland

24 E-mail: mia.siven@helsinki.fi 
3

\section{Abstract}

Objectives: The study evaluated the quality of compounded sachets and hard gelatine capsules and their feasibility in paediatric drug administration.

Methods: Commercial tablets were compounded to sachets and capsules in hospital environment, and the uniformity of content and simulated drug dose were determined.

Key findings: Compounded formulations were successfully obtained for a range of drug substances; dipyridamole, spironolactone, warfarin and sotalol formulations were within acceptable limits for uniformity of content, in most cases. Though, some loss of drug was seen. The type and amount of excipients were found to affect uniformity of content; good conformity of capsules was obtained using lactose monohydrate as filler, whereas microcrystalline cellulose was a better choice in sachets. In capsules, content uniformity was obtained for a range of drug doses. If the drug is aimed to be administered through a nasogastric tube, solubility of the drug and excipients should be considered, as they were found to affect the simulated drug dose in administration.

Conclusions: Compounded sachets and capsules fulfilled the quality requirements in most cases. In compounding, the choice of excipients should be considered as they can affect conformity of the dosage form or its' usability in practice. Quality assurance of compounded formulations should be taken into consideration in hospital pharmacies.

\section{Keywords:}

Capsule, Compounding, Content uniformity, Nasogastric tube, Paediatric, Sachet 


\section{Introduction}

The lack of age-appropriate formulations for paediatric medications is faced in everyday work in hospitals. Also, off-label use of medicines is common $(1,2)$. In medication, extemporaneous preparations have to be used, although these have certain risks such as dosing inaccuracy or errors, excipient toxicity or modified bioavailability (3). Dosage forms and formulations are needed for paediatric use. In dosage forms, critical issues are dosing flexibility, accuracy and their practical handling. It has been evaluated that these issues concern even a quarter of existing dosage forms (3). Improvement needs concern even half of the marketed drug products when the ease of intake and palatability of the dosage form are taken into account. In improving the pharmaceutical quality of paediatric medicines the priority is on the youngest age groups, neonates and infants. Fortunately, an increased trend in the marketing authorisation procedures has been seen recently (4).

Thus far, the need for compounding commercial products to paediatric dosage forms prevail in hospitals. The choice of dosage form type vary in different European countries (5). Liquid preparations are predominant in England and Sweden, capsules in France and powders in Finland. Also other manipulations, such as tablet splitting into segments or opening capsules are often necessary in paediatric medications (6), but risk for dose inaccuracy and chanced bioavailability is apparent in these manipulations $(7,8,9)$. Facilities, time and expertise in hospital pharmacies limit the choice of what kind of compounded dosage forms are usually prepared (5). The practice in manufacture varies in the hospitals throughout Europe and there is little harmonisation of formulations. Many formulations are developed in-house, based on the literature available (if any). The quality of the formulations is usually evaluated indirectly, based on the batch records of procedures and ingredients. Often limited facilities are available for quality assurance, such as analytical equipment for evaluations of uniformity of content or stability of the drug.

In Finland, compounding to solid dosage forms is common in hospital pharmacies; a commercial tablet is crushed and diluted with an appropriate filler and redistributed in smaller 
strength sachets (powder paper) or capsules to obtain appropriately sized dosage units for paediatric medication (10). In practice, compounding to solid dosage forms has been considered feasible because solids are suitable for drug substances that are unstable in aqueous environment and thus cannot be compounded to suspensions or solutions (11). In general, solid dosage forms are expected to have better stability of the drug, although only few results of stability studies have been published for compounded capsules $(12,13)$. Additionally, solid dosage forms may be preferable because less excipients are needed (14). This is important because many common excipients exhibit potential risk for toxicity in paediatric patients (15).

However, little published information exists on compounded oral solid dosage forms, sachets and capsules. The information is in-house knowledge, and may be limited due to the lack of analytical facilities in hospital pharmacies. A Finnish research group has studied compounded sachets and hard gelatine capsules of one drug, nifedipine $(10,16,17)$. They concluded that the optimum powder mass in sachets should be $300 \mathrm{mg}$ or more, in smaller powders drug loss during manufacture increase the risk for non-conformity and low drug recovery. On the other hand, it was possible to prepare small capsules (size numbers 3 and 4), which complied the standards for uniformity of content. A French study evaluated the effect of the amount of the active ingredient on conformity of capsules, concluding that small amounts of drug increase the risk for non-conformity (18).

Extemporaneous formulations that meet the quality standards could be compounded in these studies, but not all the formulations were such. It is evident that more information is needed, on more drug substances as well as on formulations containing different kinds of excipients. Although compounded formulations should be avoided, they still need to be used in hospitals. Thus, all the work towards compounded products which would be safe in use is extremely important.

In the present study, the real life compounding of solid dosage forms in hospital pharmacy was mimicked, using the procedures and facilities available. The quality of sachets and hard gelatine capsules was evaluated, by determining their content uniformity as described in the European 
97 Pharmacopoeia. Furthermore, the usability of the compounded solid dosage forms in paediatric drug administration was evaluated by mimicking the real administration procedure in hospitals (drug administration via nasogastric tube). In practice, the dosage form is opened before administration and the contents are administered with fluid or food (5). In the younger patients, the contents are

101 suspended in water and administered through a nasogastric tube. Administration has been found

102 challenging due to occasional blockage of the tube $(19,20)$. The present study evaluated whether the formulation could explain difficulties in administration. excipients in formulations. Drug substances were chosen based on their prevalence as commonly modified products in Finnish hospital pharmacies; dipyridamole, spironolactone, warfarin and

107 sotalol. Additionally, warfarin and spironolactone were chosen based on their status as drugs 108 included on the WHO Model List of Essential Medicines for Children (21). Although these drug 109 substances are widely used in paediatric medication, no published information on the quality of 110 compounded sachets or capsules is available. The risk for non-conformity was expected to be most 111 evident with small-dose drugs (18). Thus, the effect of drug amount was studied with spironolactone 112 and warfarin, which have the lowest therapeutic dose (of the four drugs). Sachets and capsules of 113 different sizes were prepared, by varying the amount of filler in the formulation. Microcrystalline 114 cellulose and lactose monohydrate were chosen because they are both widely used as excipients in 115 paediatric medicines. Different grades of excipients were evaluated; microcrystalline cellulose, 116 silicified microcrystalline cellulose and two grades of lactose monohydrate. These were chosen on 117 the basis of their particle size and flow properties, which are expected to be important variables in 118 preparation of the sachets and in the filling procedure of capsules which is standardized by volume 119 (10). The effect of excipient grade was evaluated in more detail with sachets of the smallest weight. 120 As the sachets are filled with weight, small weight sachets are expected to be most sensitive to dose 121 non-conformity. 


\section{Materials and methods}

124

126

\section{Materials in compounding}

Commercial tablets were compounded to sachets and hard gelatine capsules. Drug substances in these were dipyridamole (Dipyrin $75 \mathrm{mg}$, Ratiopharm; Merckle, Germany), spironolactone (Spirix $25 \mathrm{mg}$, Takeda Pharma, Denmark), warfarin as a sodium salt (Marevan forte $5 \mathrm{mg}$, Orion Pharma, Finland) and sotalol as a hydrochloride salt (Sotalol Mylan 80 mg, Mylan; Gerard Laboratories, Ireland).

Microcrystalline cellulose (MCC; Avicel PH-102, FMC Biopolymer, Ireland), silicified microcrystalline cellulose (SMCC; Prosolv 50, Penwest Pharmaceuticals Co, USA) and two grades of lactose monohydrate (Pharmatose, 200M and $80 \mathrm{M}$, DMV International, Netherlands) were used as fillers in formulations. Lactose monohydrate is freely but slowly soluble in water (1 in 5.24) whereas the celluloses are practically insoluble in water (22). In the MCC the average particle size was $100 \mu \mathrm{m}$ and the values for bulk density and tapped density were $0.32 \mathrm{~g} / \mathrm{cm}^{3}$ and $0.48 \mathrm{~g} / \mathrm{cm}^{3}$, respectively. In the SMCC the corresponding values were $60 \mu \mathrm{m}, 0.31 \mathrm{~g} / \mathrm{cm}^{3}$ and $0.39 \mathrm{~g} / \mathrm{cm}^{3}$. In Pharmatose $200 \mathrm{M}$ the particle size was $<250 \mu \mathrm{m}$ (fine particle fraction $60 \%<45 \mu \mathrm{m}$ ) and values for bulk and tapped densities were $0.55 \mathrm{~g} / \mathrm{cm}^{3}$ and $0.85 \mathrm{~g} / \mathrm{cm}^{3}$, respectively. In Pharmatose $80 \mathrm{M}$ the particle size was $<355 \mu \mathrm{m}$ (fine particle fraction $10 \%<100 \mu \mathrm{m}$ ), and the respective values for bulk and tapped densities were $0.76 \mathrm{~g} / \mathrm{cm}^{3}$ and $0.91 \mathrm{~g} / \mathrm{cm}^{3}$.

\section{Compounding to sachets and hard capsules}

Preparation of the sachets and hard capsules were done according to the standard protocol for extemporaneous compounding of dosage forms in hospital pharmacy, using the equipment and facilities available (Helsinki University Hospital, Finland, Päijät-Häme Central Hospital, Finland). Manufacturing procedures are the same in these units, but the choice of excipients in formulations 
147 differ slightly (lactose is preferred in the first unit whereas MCC in the second).

148 The commercial tablets were crushed manually and carefully ground into a fine powder, with

149 a pestle in a non-porous mortar. The pestle was held firmly and downward pressure was exerted with

150 it while the pestle was moved in concentric circles. Geometric amounts of filler were added to

151 achieve a final drug concentration in formulation. Sachets were prepared to total weight of $200 \mathrm{mg}$

152 (dipyridamole), $300 \mathrm{mg}$ (sotalol) or $500 \mathrm{mg}$ (spironolactone or warfarin). The theoretical amount of

153 each drug was $5 \mathrm{mg}$ (dipyridamole), $4 \mathrm{mg}$ (sotalol), $0.5 \mathrm{mg}$ (spironolactone) and $0.1 \mathrm{mg}$ (warfarin).

154 Each powder was weighed individually using an analytical balance (precision $\pm 0.05 \mathrm{mg}$ ) and

155 transferred into waxed powder papers (Ulvila Paper Mill, Finland). One batch of each formulation

156 was prepared for the production of 100 sachets.

157 In preparation of the capsules, the amount of filler needed to fill the capsule was calculated

158 and geometric amounts of filler were added to ground tablet mass to achieve the final volume of

159 capsules. Hard gelatine capsules number 0 (volume $0.68 \mathrm{ml}$ ) were used for spironolactone and

160 warfarin formulations, and capsules number 1 (volume $0.5 \mathrm{ml}$ ) were used for sotalol formulation. The

161 theoretical amount of the drug in capsules was the same as in the sachets. Additionally, capsules

162 containing higher amounts of drug were prepared for spironolactone and warfarin. Drug doses were 4

$163 \mathrm{mg}$ for sotalol, $0.5 \mathrm{mg}, 3 \mathrm{mg}$ and $6 \mathrm{mg}$ for spironolactone and $0.1 \mathrm{mg}, 0.2 \mathrm{mg}$ and $2 \mathrm{mg}$ for warfarin.

164 Capsules were filled with the Feton Fastlock capsule filling machine (Feton International, Belgium).

165 Parallel batches were prepared for the production of 100 hard capsules. Because the capsules are

166 filled with volume, variation in the powder mass and thus variation in the filling procedure may result

167 in batch to batch variability.

168 As a comparison to the semi-automated procedure (Feton) which is commonly used in

169 Finnish hospitals, capsules were prepared with an automated procedure. These capsules were

170 manufactured by Mettler Toledo Gmbh (Switzerland), using an automated Quantos capsule filling

171 device (QH012-LNM, Mettler Toledo AG, Switzerland). The powder mass was prepared in hospital 
172 pharmacy, as described previously, and the obtained drug powder was sent to Mettler Toledo for

173 capsulation. The reference capsules contained the lowest amount of drug; spironolactone $(0.5 \mathrm{mg}) \mathrm{or}$

174 warfarin $(0.1 \mathrm{mg})$.

175

176 Drug analysis by HPLC

177 Drug concentrations were determined by means of high performance liquid chromatography

178 (HPLC). Previously described methods with slight modifications were used in analysis (dipyridamole

179 (23), spironolactone (24); warfarin sodium (25); sotalol hydrochloride (26)). Samples containing

180 sotalol hydrochloride were analysed in the Department of Environmental Sciences, all the other drugs

181 were analysed in the Division of Pharmaceutical Chemistry and Technology.

182 The HPLC system (Shimadzu Corporation, Japan, for sotalol hydrochloride; Thermo

183 Separation Products TSP, USA, for the other drugs) consisted of degasser (Shimadzu DGU-20 A5;

184 TSP Spectra System SCM 1000 vacuum membrane degasser), a pump (Shimadzu LC-20AT; TSP

185 Spectra System P4000), autosampler (Shimadzu SIL-20-A; TSP Spectra System SA 3000), a UV-

186 VIS detector (Shimadzu SPD-20A; TSP Spectra System UV 6000 LP) and a computerized data

187 analysis system (Shimadzu Corporation LabSolutions 5.57 SP1, Japan; CromQuest 4.2.32, Thermo

188 Scientific, USA).

189 Sample separation was carried out in a reverse phase C-18 column (Synergi Hydro-RP 4.6

$190 \mathrm{~mm}$ x $25 \mathrm{~cm} ; 4 \mu \mathrm{m}$, USA for sotalol hydrochloride; Supelco Discovery $4.66 \mathrm{~mm}$ x $15 \mathrm{~cm} ; 5 \mu \mathrm{m}$, USA

191 for the other drugs). Retention times varied from 4.3 to 4.7 minutes for the analytes.

192 The mobile phase consisted of methanol and phosphate buffer $\mathrm{pH} 4.6$ (in a ratio of 75:25) for

193 dipyridamole. For spironolactone, the mobile phase was methanol and HPLC grade water (65:35).

194 For warfarin sodium, the mobile phase consisted of acetonitrile and HPLC grade water with $0.05 \%$ of

195 trifluoroacetic acid (55:45). For sotalol hydrochloride, the mobile phase was acetonitrile and

196 phosphate buffer $\mathrm{pH} 4.6(75: 25)$. The flow rate of the mobile phase was $1.0 \mathrm{ml} / \mathrm{min}$. 
Uniformity of content

Content uniformities of dosage units (commercial tablets and compounded solid formulations

thereof) were determined by method established in the European Pharmacopoeia. The dosage unit

complied the test if not more than one of 10 individual contents was beyond $\pm 15 \%$ of the average content and if none were beyond $\pm 25 \%$ of the average content. If two or three individual contents deviated more than $\pm 15 \%$ (but less than $\pm 25 \%$ ), the individual contents of another 20 dosage units were determined. The drug concentrations were analysed in triplicate by HPLC.

Statistical analysis

Statistical analysis were carried out in SPSS (IBM SPSS Statistics, Ver. 23, United States) using non-parametric Kruskal-Wallis analysis of variance. Individual differences were identified using Dunnet's two-tailed t-test as a post hoc test. The value $\mathrm{P}<0.05$ was considered as statistically significant.

\section{Simulation of drug administration}

Dosage form administration to paediatric patients in hospitals was simulated mimicking the

214 administration procedure through a nasogastric tube (Helsinki University Hospital, Finland, Päijät-

215 Häme Central Hospital, Finland). Individual contents of the dosage forms were emptied to a

216 medicine cup and suspended to HPLC grade water. The volume of water varied depending on the

217 procedure that they use in the hospital; 1.5 millilitres of water was used for suspending the contents

218 of size 1 hard gelatine capsules, and for suspending the contents of size 0 hard gelatine capsules or 219 sachets the volume was 3 millilitres. The suspension was thoroughly stirred with the tip of an oral 220 syringe (volume $5 \mathrm{ml}$ ) after which the formed suspension was withdrawn into the syringe for drug 221 administration. Nasogastric tube (Nutrisafe 2, size 06 French/50 cm, internal diameter $1.2 \mathrm{~mm}$, 
222

external diameter $2 \mathrm{~mm}$, VYGON, France) was first rinsed with 2 millilitres of water, after which the drug suspension was administered through the tube. Finally, the tube was rinsed with 2 millilitres of water. All contents were led to a volumetric flask and after diluting the sample to a known volume, the amount of drug was analysed by HPLC. The simulated drug dose passed through the nasogastric tube was expressed as percentage of the average amount of the drug in formulation. The procedure was repeated in triplicate for each formulation.

\section{Results}

\section{Content uniformity of commercial tablets}

All commercial tablets complied the test for uniformity of content, as expected. The average contents of drug in tablets were $77.6 \mathrm{mg} \pm 3.5 \mathrm{mg}(\mathrm{SD})$ for dipyridamole $(103.5 \%$ of the theoretical drug amount, which was labelled to be $75 \mathrm{mg}$ ), $24.2 \mathrm{mg} \pm 0.3 \mathrm{mg}$ for spironolactone ( $98 \%$ of the labelled amount $25 \mathrm{mg}), 4.96 \mathrm{mg} \pm 0.08 \mathrm{mg}$ for warfarin $(99.2 \%$ of the labelled amount $5 \mathrm{mg}$ ) and $72.1 \mathrm{mg} \pm 1.4 \mathrm{mg}$ for sotalol (90.1\% of the labelled amount $80 \mathrm{mg})$.

\section{Content uniformity of compounded sachets}

The content uniformity of sachets, compounded with different fillers as excipients, complied the test for uniformity of content for most formulations (Table 1). However, if lactose of smaller particle size $(<250 \mu \mathrm{m})$ or microcrystalline cellulose were used as fillers, the formulation failed to comply with the test. In case of MCC formulations, two individual contents were outside the limits 85 per cent to 115 per cent of the average content, and one was outside the limit of 75 per cent to 125 per cent, in which case the deviation was $26.3 \%$ of the average content. For lactose formulation (particle-size grade $<250 \mu \mathrm{m}$ ), one content was outside the limit of 75 per cent to 125 per cent (measured value $-30.7 \%$ ). The average drug content in formulations containing the different 
excipients (MCC, SMCC or lactose, two grades) was found statistically significantly different $(\mathrm{P}<0.05)$ (Table 1).

Although most of the formulations complied the test for uniformity of content, the mean drug content in compounded sachets was in most cases less than the theoretical drug content (Table 1). The difference was statistically significant $(\mathrm{P}<0.05)$ for most of the formulations $(5 / 7)$. The adsorption of the drug in powder paper seemed one possible explanation for the loss of active ingredient, as visualised in Figure 1 for the yellowish drug dipyridamole. At highest, 16\% (0.8 mg; $\mathrm{SD} \pm 0.13 \mathrm{mg} ; \mathrm{n}=5$ ) of the labelled dose of dipyridamole was recovered from the sachet paper (formulation containing lactose particle-size grade $<355 \mu \mathrm{m}$ ). In analysis, the paper was rinsed with water and the drug analysed by HPLC. The drug loss was smallest when SMCC was used as filler in sachets, $3.8 \%(0.2 \mathrm{mg}$; $\mathrm{SD} \pm 0.02 \mathrm{mg} ; \mathrm{n}=5)$ of the labelled dose of dipyridamole was recovered from the sachet paper. The rest of the missing dose was assumed to be on the manufacturing tools.

\section{Content uniformity of compounded capsules}

The content uniformity of hard capsules compounded using lactose as filler complied the test for uniformity of content (Table 2). Content uniformity of hard capsules of spironolactone and warfarin were studied at three different dose levels. The largest single-capsule deviation from the mean content was $21 \%$ for capsules that contained the lowest amount of spironolactone $(0.5 \mathrm{mg})$. The measured mean drug content in the batch was $0.42 \mathrm{mg}$ which was lower $(\mathrm{P}<0.05)$ than the theoretical amount of drug ( $84.4 \%$ of the labelled dose). Also for warfarin, the highest single-capsule deviation

$267(-8.2 \%)$ was observed with a batch of capsules which contained the lowest amount of drug $(0.1 \mathrm{mg})$.

268 In the batch, the measured mean drug content was $90 \%$ of the theoretical amount of drug, although the effect was not statistically significant in this batch. 
272 of three did not comply the test for uniformity of content (Table 2). The highest single-capsule

273 deviation was $25.2 \%$ which was slightly above the upper acceptation limit. In all batches the

274 measured mean drug content was lower compared to the theoretical amount of the drug (4 mg). The

275 average amount of drug varied from $3.7 \mathrm{mg}(\mathrm{SD} \pm 0.09 \mathrm{mg}, \mathrm{P}<0.05)$ to $3.72 \mathrm{mg}$ ( $\mathrm{SD} \pm 0.39 \mathrm{mg}$,

$276 \mathrm{P}<0.05)$, which corresponded $92.5 \%$ to $93.0 \%$ of the theoretical amount of the drug.

277 In most cases, no statistically significant effects were found in relation to batch to batch

278 variation. Only two batches out of 15 parallel batches differed significantly $(\mathrm{P}<0.05)$ in the average

279 drug content (Table 2).

280 Capsules were also prepared with an automated Quantos capsule filling device, as a

281 comparison to the conventional method (Feton). The batches prepared using Quantos complied with

282 the content uniformity test specified in the European pharmacopoeia, as expected. Segregation of

283 powder components during the filling process was not observed (Figure 2). The filling method had

284 no effect on the quality of the capsules, and no statistically significant differences were found in the

285 average drug content if capsules filled with Quantos were compared to capsules filled with the

286 conventional method. The largest single-capsule deviation from the mean content was $10 \%$

287 (spironolactone 10.24\%; warfarin 10.20\%; filler lactose). The average amount of drug in capsules

288 was $0.41 \mathrm{mg}(\mathrm{SD} \pm 0.017 \mathrm{mg})$ for spironolactone and $0.093 \mathrm{mg}(\mathrm{SD} \pm 0.0038 \mathrm{mg})$ for warfarin,

289 which corresponded $82.0 \%$ and $93.0 \%$ of the theoretical amount of the drug $(0.5 \mathrm{mg}$ and $0.1 \mathrm{mg}$ for

290 spironolactone and warfarin, respectively). The difference in drug amount was statistically significant

$291 \quad(\mathrm{P}<0.05)$ for spironolactone (no statistical effects were found for warfarin).

Simulation of drug administration through a nasogastric tube

The loss of drug was evident when suspended formulations were lead through a nasogastric

295 tube, mimicking the procedure used in hospitals in administering the drug to the paediatric patient.

296 The lowest simulated drug doses were obtained with sachets that contained celluloses (MCC or 
297 SMCC) as fillers, compared to formulations that contained lactose. In these, the amount of 298 dipyridamole passed through the nasogastric tube $(\mathrm{n}=3)$ varied from $46.5 \%$ (SMCC) and $62.0 \%$ 299 (MCC) to $77.5 \%$ (lactose $<355 \mu \mathrm{m}$ ) and $86.1 \%$ (lactose $<250 \mu \mathrm{m}$ ) of the average drug content. 300 In compounded hard gelatine capsules the drug loss was smaller than $12 \%$ of the average drug 301 content in all cases. For size 0 hard gelatine capsules, the drug dose passed through the nasogastric 302 tube ( $\mathrm{n}=3$ ) was $88.1 \%$ for spironolactone and $96.4 \%$ for warfarin (as sodium salt), calculated of the 303 average drug content in the capsules. The filler in these capsules was lactose (particle-size grade < $304355 \mu \mathrm{m})$. For size 1 hard gelatine capsules, $90.3 \%(\mathrm{n}=10, \mathrm{P}<0.05)$ of the drug dose passed through 305 the tube (drug sotalol hydrochloride, filler MCC).

Blockage of the nasogastric tube during drug administration was occasional, in most cases

307 with no clear correlation to the type of the formulation. However, some tendency towards more 308 frequent blockage was observed with formulation in which there was a combination of the slightly 309 soluble drug dipyridamole and the practically insoluble, but swellable excipients MCC or SMCC.

\section{Discussion}

Finnish studies have presented extemporaneously compounded oral powders and capsules as a feasible choice for delivering paediatric medications (nifedipine) in hospital environment $(10,16,17)$.

314 The results of the present study demonstrate that, when needed, compounded solid dosage forms can 315 successfully be obtained also for a range of other drug substances which are commonly used in 316 paediatric medication in Finnish hospitals; in most cases, formulations of dipyridamole,

317 spironolactone, warfarin and sotalol were found to be within acceptable limits for content uniformity, 318 as described in the European Pharmacopoeia. In statistical analysis, no significant differences existed 319 in average drug content when sachets were compared to capsules, indicating that both dosage forms 320 are as good as a choice. However, the actual drug content in both dosage form types, sachets and hard 321 gelatine capsules, was generally smaller than the theoretical amount of the drug. In 19 batches out of 
24 the difference was statistically significant $(\mathrm{P}<0.05)$.

The findings on lower drug contents compared to the theoretical drug amount could partly be explained by the fact that the commercial tablets, which were used as a source of the active drug substance, may have contained less drug than labelled. Although the amount of drug was on an acceptable level in all products, the commercial tablets are allowed to have this kind of specific variation in drug content. Additionally, the drug adsorption on the surface of the dispenser or the loss of drug during the preparation process are possible explanations for low drug recovery $(10,16)$. The drug loss has been found to be more marked with small size oral powders (mass $50 \mathrm{mg}$ or $100 \mathrm{mg}$ ) dispensed in sachets, in which the drug recovery was only $62-77 \%$ of the theoretical value. A total of $75 \%$ of the missing drug dose was found on the sachet paper (16). In compounded capsules (capsule shells size 1,3 or 4 ) the drug recovery was satisfactory, which apparently related to the smaller surface area of the dispenser; capsule shell compared to sachet paper (10). In our study, the dosage units were in general larger (mass in the sachets varied from $200 \mathrm{mg}$ to $500 \mathrm{mg}$, and the capsule shell size from 1 to 0 ) than in the previous study and thus, not so marked drug loss was expected.

However, the phenomenon of drug adsorption on the surface of the sachet paper was easily visualised with the yellowish drug dipyridamole. In analysis, at highest $16 \%$ of the theoretical dose was found on the sachet paper (formulation containing lactose as filler). The risk of drug loss should be kept in mind in sachet formulations, especially if small sachets are prepared. Also, further studies would be beneficial in evaluations on whether other sachet materials than waxed powder paper could result in smaller drug loss, such as plastic laminates or foil.

Although sachets and hard gelatine capsules were successfully compounded from commercial tablets in most cases, our results emphasize that the type and amount of excipients in the formulation should be considered as they can affect conformity of the dosage form. In statistical analysis, the effect of excipient was found significant in all cases, and formulations which contained the different excipients (MCC, SMCC and lactose, two grades) differed in average drug content. If the quality of 
the formulations was evaluated as described in the European Pharmacopoeia, in total of three batches

348 (out of 24 batches) failed to pass the test for content of uniformity; two of these were compounded as 349 sachets (weight $200 \mathrm{mg}$ ) and one was a batch of hard gelatine capsules (capsule size 1). The sachets 350 are filled by weight, and therefore inaccuracy of weighing procedures of the small amounts may be a 351 challenge (10). Consistently in our study, the non-conformity in sachets was observed in the smallest 352 sachet mass. Drug adsorption on the surface of the sachet paper or the equipment during preparation 353 seemed possible explanations for non-conformity, as discussed earlier for sachets containing lactose

354 (drug dipyridamole). It has been proposed that use of microcrystalline cellulose as filler could yield 355 in better conformity in sachets (10). The smaller density of MCC results in larger volume of powder, 356 which may protect against the drug adsorption to the sachet paper. Our results emphasise that in 357 addition to density, also other powder characteristics may be important. The best drug recovery and 358 less variation in uniformity of content of dipyridamole was obtained with silicified MCC, in which 359 case not only the small density of the filler but also the surface properties of the excipient, such as 360 hydrophobicity, may explain the results. Whereas the sachets are filled by weight, capsules are filled with volume. Thus, in preparation 362 of capsules good flow properties of the filler are expected to result in better conformity (10). In 363 general, higher density grades of fillers have improved flow properties (27). In addition, the amount 364 of drug is known as a critical variable in compounded capsule formulations, and small amounts of 365 drug increase the risk for non-conformity (18). In the present study, all 14 batches of capsules which 366 contained lactose as filler complied the test for uniformity of content. On the other hand, in MCC 367 capsules one batch of capsules out of three failed the test. The good conformity of lactose capsules 368 may be explained by the high bulk and tapped densities of lactose, which could result in uniform 369 filling of capsule shells during the manufacturing process. It was noteworthy, that content uniformity 370 (as described in the European Pharmacopoeia) was obtained for a range of drug doses (from $0.1 \mathrm{mg}$ 371 to $2 \mathrm{mg}$ for warfarin and from $0.5 \mathrm{mg}$ to $6 \mathrm{mg}$ for spironolactone), including the small doses of the 
372 drug. In most cases, no statistically significant effects were found in relation to batch to batch

373 variation. This indicates that compounding of such formulations is rather reproducible. However, it

374 should be noted that the measured drug content in the batches was predominantly significantly lower

375 than the theoretical amount of the drug, although the batches met the pharmacopeial requirements.

376 Discrepancy between the results could be explained by the fact that the limits of acceptance are

377 calculated of the average drug content of the batch (instead of labelled drug amount).

378 The last part of the study evaluated the practical usability of compounded sachets and

379 capsules. Both sachets and capsules, whose contents are emptied for use, seem feasible choice from

380 quality perspective (uniformity of content), and are a practical choice for manufacture in hospital

381 pharmacies. In comparison to sachets, manufacture of capsules is faster as serial production can be

382 utilised. This increases the usability of compounded capsules even further. Capsules filled with the

383 Feton Fastlock filling machine were as good in quality as the reference capsules which had been

384 filled using the automated Quantos capsule filling device. Despite of these favourable properties,

385 there might be some concerns in practical use of compounded sachets and capsules. Including the

386 capsules prepared with the Quantos capsule filling device, the risk of drug loss in manufacture and

387 consequent possibility to under dosing should be considered. In addition, administration of these

388 kinds of solid dosage forms (suspended in fluid) through the nasogastric tube has been found

389 challenging $(19,20)$. The volume of water (or other fluid such as milk) in which the solid powder is

390 suspended, should be rather small as the daily intake of fluids in the neonates is limited. The small

391 volume of fluid increases, however, the risk of blockage of the nasogastric tube. In our study, the

392 administration through a nasogastric tube resulted in loss of drug. The lowest simulated drug doses

393 were obtained with sachets which contained the slightly soluble (but swellable) excipient,

394 microcrystalline cellulose, compared to formulations which contained the more readily soluble

395 lactose. Similarly, the amount passed through the tube was slightly less for the insoluble drug

396 spironolactone than for the readily soluble warfarin sodium. Such drug loss in administration, 
together with the fact that the actual dose of drug was in most formulations less than the theoretical dose, increases the risk for under dosing in practice, especially for the drugs of narrow therapeutic index (such as warfarin in the present study).

The results emphasize that in compounded sachets and capsules (if the dose is aimed to be administered through a nasogastric tube) solubility of the drug and excipients should be considered. The amount of solid contents should also be as small as possible as the amount of liquid used for suspending cannot be increased due to physiological reasons. This is supported by findings for size 1 capsules, in which the drug administration through nasogastric tube resulted in high simulated drug dose, even though the formulation contained the slightly soluble excipient MCC. Also from the therapeutic point of view, smaller amount of excipients would be preferable as the safety of many excipients in the very young patients is not known (15). In practice, this means preference for compounding sachets of small weight and capsules of small size. The risk of drug loss should, however, be kept in mind.

It is evident that more studies are needed in evaluations on how the formulation and excipients, or their administration procedure to the patient affect bioavailability of extemporaneous formulations. Also, in vitro studies predicting biological properties of the developed formulations are needed, such as dissolution studies. Unfortunately, the lack of facilities (analytical facilities, dissolution apparatus etc.) in hospital pharmacies has limited conductance of these studies.

\section{Conclusions}

Our results indicate that compounded formulations, which meet the quality requirements for uniformity of content as described in the European Pharmacopoeia, can successfully be obtained for a range of drug substances. The results emphasize, however, that the type and amount of excipients in the formulation should be considered. Good conformity of capsules was obtained using lactose monohydrate as filler, whereas microcrystalline cellulose seemed a better choice in sachets. In lactose 
422 capsules content uniformity could be obtained for a range of drug doses, including the very small

423 doses. If the drug is aimed to be administered through a nasogastric tube, solubility of the drug and

424 excipients should be considered, as they were found to affect the simulated drug dose in

425 administration. The risk of drug loss should be considered in manufacture and administration. It is

426 noteworthy that even though the formulations met quality requirements for uniformity of content, in

427 most cases the measured drug content was statistically significantly lower than the theoretical amount

428 of the drug.

429 Both sachets and capsules could be a practical choice as solid dosage forms to be prepared in

430 hospital pharmacies. Capsules are faster to manufacture, which increases their value even more

431 compared to sachets. It is obvious, however, that validation of manufacturing procedures and quality

432 assurance systems are important in hospital pharmacies, as the conformity is affected by the

433 formulation. In compounding, the risk of drug loss should be kept in mind and analytical methods

434 would be needed to determine the drug amount in quality analysis, or the influence of procedures

435 (crushing the tables) on drug. Additionally, compatibility and stability studies are needed if

436 compounded formulations are manufactured for storage, in addition to extemporaneous preparation.

437 Dissolution studies would be needed to predict the biological properties of the developed

438 formulations.

\section{Acknowledgements and funding}

Personnel of the Helsinki University Hospital (Finland) and the Päijät-Häme Central Hospital

442 (Finland) are acknowledged for their expertise and counselling.

443 This research received no specific grant from any funding agency in the public, commercial,

444 or not-for-profit sectors. 


\section{References}

1. Conroy S, Choonara I, Impicciatore P, Mohn A, Arnell H, Rane A, Knoeppel C, Seyberth H, Pandolfini C, Raffaelli MP, Rocchi F, Bonati M, Jong G, de Hoog M, van den Anker J.. Survey of unlicensed and off label drug use in paediatric wards in European countries. European Network for Drug Investigation in Children. BMJ 2002; 320: 79-82.

2. Turner S, Longworth A, Nunn AJ, Choonara I. Unlicensed and off label drug use in paediatric wards: prospective study. BMJ 1998; 316: 343-345.

3. European Medicines Agency (EMA) 2012: 5-year Report to European Commission, General report on the experience acquired as a result of the application of the Paediatric Regulation. EMA/428172/2012; http://ec.europa.eu/health/files/paediatrics/2012-09_pediatric_report-annex12 en.pdf. (accessed 28 March 2016).

4. European Medicines Agency (EMA) 2015. Annual report on benefits and infringements under the Paediatric Regulation. EMA/133100/2015; http://ec.europa.eu/health/human-use/paediatricmedicines/developments/index en.htm. (accessed 28 March 2016)

5. Brion F, Nunn AJ, Rieutord A. Extemporaneous (magistral) preparation of oral medicines for children in European hospitals. Acta Paediatr 2003; 92: 486-490.

6. Standing JF, Tuleu C. Pediatric formulations- Getting to the heart of problem. Int J Pharm 2005; 300: 56-66.

7. Teng J, Song CK, Williams RL, Polli JE. Lack of medication dose uniformity in commonly split tablets. J Am Pharm Assoc 2002; 42: 195-199.

8. Rosenberg JM, Nathan JP, Plakogiannis F. Weight variability of pharmacist-dispensed split tablets. J Am Pharm Assoc 2002; 42: 200-205.

9. Breitkreutz J, Wessel T, Boos J. Dosage forms for peroral drug administration to children. Paediatr. Perinatal Drug Ther 1999; 3: 25-33.

10. Helin-Tanninen M, Naaranlahti T, Kontra K, Savolainen K. Nifedipine capsules may provide a viable alternative to oral powders for paediatric patients. J Clin Pharm Ther 2007; 32: 49-55.

11. Woods DJ 1997. Extemporaneous formulations: problems and solutions. Pediatr Perinat. Drug Ther 1997; 1: 25-29.

12. Barnes AR, Nash S. Stability of bendroflumethiazide in a low-dose extemporaneously prepared capsule. J Clin Pharm Ther 1994; 19: 89-93.

13. Fortner J, Salton J, Carlson C, Wheeler R, Cote B, Rao D. Solid state stability of extemporaneously prepared levothyroxine aliquots and capsules. Int J Pharm Compd 2015; 19(5): 414-419.

14. Stoltenberg I, Breitkreutz J. Orally disintegrating mini-tablets (ODMTs) - A novel solid oral dosage form for paediatric use. Eur J Pharm Biopharm 2011; 78: 426-469.

15. Ernest TB, Elder DP, Martini LG, Roberts M. Developing paediatric medicines: identifying the needs and recognizing the challenges. J Pharm Pharmacol 2007; 59: 1043-1055. 
16. Helin M, Kontra K, Naaranlahti T, Wallenius K. Content uniformity and stability of nifedipine in extemporaneously compounded oral powders. Am J Health-Syst Pharm 1998; 55: 1299-1301.

17. Helin-Tanninen M, Naaranlahti T, Kontra K, Wallenius K. Enteral suspension of nifedipine for neonates. Part 1. Formulation of nifedipine suspension for hospital use. J Clin Pharm Ther 2001; 26: 49-57.

18. Mathaut S, Bordenave J, Fratta A, Benoit G. Quality control of hospital preparations: results concerning capsules production in a child hospital. Annal Pharmaceutiq Franc 2006; 64: 44-51.

19. Williams NT. Medication administration through enteral feeding tubes. Am J Health-Syst Pharm 2008; 65: 2347-2357.

20. Belknap DC, Seifert CF, Petermann M: Administration of medications through enteral feeding catheters. Am J Crit Care 1997; 6 (5): 382-92.

21. World Health Organization (WHO) 2010. WHO Model List of Essential Medicines for Children http://www.who.int/medicines/publications/essentialmedicines/Updated_second_children_list_en.pdf (accessed 28 March 2016)

22. Rowe RC et al. eds. Handbook of Pharmaceutical Excipients.Eds., 7th edn. Pharmaceutical Press, 2012

23. Allen LV Jr, Erickson M A: Stability of baclofen, captopril, diltiazem hydrochloride, dipyridamole, and flecainide acetate in extemporaenously compounded oral liquids. Am Society of Health Syst Pharm 1996; 53: 2179-2184.

24. Alexander KS, Vangala SS, Dollimore D. An improved high-performance liquid chromatography assay for spironolactone analysis. Drug Dev Ind Pharm. 1998; 24(2):101-107.

25. Ghimenti S, Lomonaco T, Onor M, Murgia L, Paolicchi A, Fuoco R, Ruocco L, Pellegrini G, Trivella MG, Di Francesco F. Measurement of Warfarin in the Oral Fluid of Patients Undergoing Anticoagulant Oral Therapy. PLoS One 2011; 6(12):e28182. doi: 10.1371/journal.pone.0028182.

26. Santoro MIRM, Tsubone C, Gomes FP, Kedor-Hackmann ERM, García PL. Development and validation of high performance liquid chromatographic and UV - derivative spectrophotometric methods for the determination of sotalol hydrochloride in tablets. Anal Letters 2008; 41(11): 20442057.

27. Lahdenpää E, Niskanen M, Yliruusi J. Study of some essential physical characteristics of three Avicel PH grades using a mixture design. Eur J Pharm Biopharm 1996; 42: 177-182. 


\section{TABLES}

Table 1. Uniformity of content in compounded sachets. Individual contents of at least 10 units were determined, as described in the method by European Pharmacopoeia.

\begin{tabular}{|c|c|c|c|c|c|}
\hline $\begin{array}{l}\text { Drug; } \\
\text { Excipient }\end{array}$ & $\begin{array}{l}\text { Average } \\
\text { drug } \\
\text { content } \\
(\mathrm{mg})\end{array}$ & $\begin{array}{l}\text { Acceptable } \\
\pm 15 \% \text { limits } \\
(\mathrm{mg})\end{array}$ & $\begin{array}{l}\text { Largest } \\
\text { individual } \\
\text { deviation } \\
(\mathrm{mg})\end{array}$ & $\begin{array}{l}\text { Maximum } \\
\text { deviation } \\
(\%)\end{array}$ & $\begin{array}{l}\text { Amount of } \\
\text { drug (\% of } \\
\text { theoretical) }\end{array}$ \\
\hline \multicolumn{6}{|l|}{ Dipyridamole $^{\mathrm{a}}$} \\
\hline MCC & $4.52^{\mathrm{f}, \mathrm{g}}$ & $3.84-5.20$ & 1.18 & +26.3 & 90.4 \\
\hline SMCC & $5.33^{\mathrm{f}, \mathrm{g}}$ & $4.54-6.13$ & 0.69 & $-12.9^{\mathrm{e}}$ & 106.6 \\
\hline Lactose $(<355 \mu \mathrm{m})$ & $4.04^{\mathrm{f}, \mathrm{g}}$ & $3.43-4.65$ & 0.52 & $+12.9^{\mathrm{e}}$ & 80.8 \\
\hline Lactose $(<250 \mu \mathrm{m})$ & $4.46^{\mathrm{f}, \mathrm{g}}$ & $3.79-5.13$ & 1.37 & -30.7 & 89.2 \\
\hline \multicolumn{6}{|l|}{ Spironolactone $\mathrm{e}^{\mathrm{b}}$} \\
\hline Lactose $(<355 \mu \mathrm{m})$ & $0.44^{\mathrm{f}}$ & $0.37-0.51$ & 0.04 & $+9.0^{\mathrm{e}}$ & 88.0 \\
\hline \multicolumn{6}{|l|}{$\begin{array}{l}\text { Warfarin (as sodium } \\
\text { salt) }\end{array}$} \\
\hline Lactose $(<355 \mu \mathrm{m})$ & 0.092 & $0.078-0.106$ & 0.009 & $+10.2^{\mathrm{e}}$ & 92.0 \\
\hline $\begin{array}{l}\text { Sotalol (as } \\
\text { hydrochloride salt) }^{\mathrm{d}} \\
\text { MCC }\end{array}$ & 3.69 & $3.14-4.23$ & 0.17 & $-4.6^{\mathrm{e}}$ & 92.2 \\
\hline
\end{tabular}


Table 2. Uniformity of content in compounded hard gelatin capsules. Individual contents of at least 10 units were determined, as described in the method by European Pharmacopoeia.

\begin{tabular}{lllllll}
$\begin{array}{l}\text { Drug; } \\
\text { Theoretical } \\
\text { drug content }\end{array}$ & $\begin{array}{l}\text { Average } \\
\text { drug } \\
\text { content } \\
(\mathrm{mg})\end{array}$ & $\begin{array}{l}\text { Acceptable } \\
\pm 15 \% \text { limits } \\
(\mathrm{mg})\end{array}$ & $\begin{array}{l}\text { Largest } \\
\text { individual } \\
\text { deviation } \\
(\mathrm{mg})\end{array}$ & $\begin{array}{l}\text { Maximum } \\
\text { deviation } \\
(\%)\end{array}$ & $\begin{array}{l}\text { Amount of } \\
\text { drug } \% \text { of } \\
\text { theoretical) }\end{array}$ & $\begin{array}{l}\text { Average } \\
\text { capsule } \\
\text { content } \\
(\mathrm{mg})\end{array}$ \\
\hline $\begin{array}{l}\text { Spironolactone } \\
0.5 \mathrm{mg}\end{array}$ & $0.424^{\mathrm{d}}$ & $0.360-0.487$ & 0.089 & $+21.0^{\mathrm{c}}$ & 84.4 & 552.4 \\
$0.5 \mathrm{mg}$ & $0.402^{\mathrm{d}}$ & $0.342-0.462$ & 0.006 & $-1.7^{\mathrm{c}}$ & 80.4 & 556.3 \\
$0.5 \mathrm{mg}$ & $0.426^{\mathrm{d}}$ & $0.362-0.489$ & 0.017 & $-4.0^{\mathrm{c}}$ & 85.2 & 553.3 \\
$3 \mathrm{mg}$ & $2.58^{\mathrm{d}}$ & $2.19-2.97$ & 0.24 & $-9.4^{\mathrm{c}}$ & 86.0 & 545.6 \\
$6 \mathrm{mg}$ & $5.25^{\mathrm{d}, \mathrm{e}}$ & $4.47-6.04$ & 0.43 & $+8.1^{\mathrm{c}}$ & 87.5 & 536.1 \\
$6 \mathrm{mg}$ & $4.88^{\mathrm{d}}$ & $4.15-5.61$ & 0.25 & $-5.2^{\mathrm{c}}$ & 81.3 & 545.8 \\
$6 \mathrm{mg}$ & $5.02^{\mathrm{d}}$ & $4.27-5.77$ & 0.18 & $-3.5^{\mathrm{c}}$ & 83.7 & 544.4 \\
& & & & & & \\
Warfarin & & & & & & \\
$(\mathrm{as} \mathrm{sodium} \mathrm{salt})^{\mathrm{a}}$ & & & & & & \\
$0.1 \mathrm{mg}$ & $0.082^{\mathrm{d}, \mathrm{e}}$ & $0.070-0.095$ & 0.006 & $-7.0^{\mathrm{c}}$ & 82.0 & 530.1 \\
$0.1 \mathrm{mg}$ & 0.094 & $0.080-0.108$ & 0.001 & $-1.2^{\mathrm{c}}$ & 94.0 & 522.1 \\
$0.1 \mathrm{mg}$ & 0.090 & $0.076-0.103$ & 0.007 & $-8.2^{\mathrm{c}}$ & 90.0 & 486.5 \\
$0.2 \mathrm{mg}$ & $0.187^{\mathrm{d}}$ & $0.160-0.216$ & 0.010 & $-5.5^{\mathrm{c}}$ & 93.5 & 512.1 \\
$2 \mathrm{mg}$ & $1.89^{\mathrm{d}}$ & $1.60-2.17$ & 0.07 & $+3.5^{\mathrm{c}}$ & 94.5 & 509.2 \\
$2 \mathrm{mg}$ & $1.84^{\mathrm{d}}$ & $1.56-2.11$ & 0.12 & $-6.5^{\mathrm{c}}$ & 92.0 & 521.0 \\
$2 \mathrm{mg}$ & $1.86^{\mathrm{d}}$ & $1.58-2.14$ & 0.07 & $+3.7^{\mathrm{c}}$ & 93.0 & 521.7
\end{tabular}

Sotalol (as

hydrochloride

salt $)^{\mathrm{b}}$

$4 \mathrm{mg}$

$3.72^{\mathrm{d}}$

$3.16-4.28$

0.13

$-3.5^{\mathrm{c}}$

93.0

186.8

$4 \mathrm{mg}$

3.70

$3.14-4.25$

0.93

$-25.2$

92.5

180.6

$4 \mathrm{mg}$

$3.70^{d}$

$3.15-4.26$

0.38

$-10.4^{\mathrm{c}}$

92.5

173.0

\footnotetext{
${ }^{\mathrm{a}}$ Capsule size 0, filler lactose monohydrate, particle-size $<355 \mu \mathrm{m}$; ${ }^{\mathrm{b}}$ Capsule size 1 , filler MCC, particle size $<$ $100 \mu \mathrm{m},{ }^{\mathrm{c}} \mathrm{Complies}$ with the test for Uniformity of Content (European Pharmacopoeia)

${ }^{\mathrm{d}}$ Statistically significantly different $(\mathrm{P}<0.05)$ from the labelled amount of drug; ${ }^{\mathrm{e}}$ Statistically significantly different $(\mathrm{P}<0.05)$ when the batch is compared to parallel batches. When capsules were compared to sachets containing the same drug substance, at the same dose (Table 1.), no statistically significant effects were detected (N.S.).
} 


\section{$515 \quad$ Figure legends}

516

517 Figure 1. Visualisation of the adsorption of the yellowish drug dipyridamole on the sachet paper.

518 Formulations (powder mass $200 \mathrm{mg}$ ) were dispensed in sachets, similarly as in preparation of the 519 compounded solid dosage forms, and emptied for analysis. Formulations contained the different 520 excipients (order of emptied sachet papers from front to back); SMCC, lactose monohydrate (particle 521 size $<250 \mu \mathrm{m}$ ), MCC and lactose monohydrate (particle size $<355 \mu \mathrm{m}$ ).

523 Figure 2. Drug content of capsules prepared using the automated Quantos (Mettler Toledo) capsule

524 filling device; upper panel spironolactone (theoretical drug amount $0.5 \mathrm{mg}, \mathrm{n}=30$ ), lower panel 525 warfarin (theoretical drug amount $0.1 \mathrm{mg}, \mathrm{n}=20$ ). The batches complied with the content uniformity 526 test, as specified in the European pharmacopoeia. The acceptance $\pm 15 \%$ limits were $0.340 \mathrm{mg}-$ $527 \quad 0.472 \mathrm{mg}$ and $0.079 \mathrm{mg}-0.107 \mathrm{mg}$ for spironolactone and warfarin, respectively. For 528 spironolactone, the drug amount was found significantly different $(\mathrm{P}<0.05)$ from the labelled amount. 529 No statistical effects were found for warfarin (N.S.). 